\section{Espírito olímpico em sala de aula: relato de uma experiência de ensino de Língua Portuguesa}

\author{
Olympic spirit in the \\ classroom: a report on a \\ Portuguese class experience
}

Marine Laísa MATTE (UFRGS) marine.laisa@gmail.com

Rosana Beatriz ERNZEN (UFRGS) rosana_ernzen@hotmail.com

\title{
00000000000
}

MATTE, Marine Laísa; ERNZEN,

Rosana Beatriz. Espírito olímpico

em sala de aula: relato de uma

experiência de ensino de Língua

Portuguesa. Entrepalavras,

Fortaleza, v. 7, p. 638-656, ago./dez. 2017.

Resumo: Este relato é fruto de uma prática de ensino de Língua Portuguesa pautada no conceito de pedagogia de projetos. As aulas foram ministradas em uma turma de $8^{\circ}$ ano do Ensino Fundamental e tiveram como temática o espírito olímpico presente nas competições OCA (Olimpíada do Colégio de Aplicação da UFRGS) e Rio 2016. A partir da problematização da temática, realizamos tarefas centradas no objeto texto, abordando recursos linguísticos relevantes para a compreensão dos gêneros trabalhados em sala de aula. Como produto final, propomos uma produção escrita que sistematizou as discussões realizadas ao longo dos doze encontros que constituíram nossa prática docente.

Palavras-chave: Pedagogia de projetos. Espírito olímpico. OCA. Rio 2016. 
Abstract: This report is a result of a Portuguese teaching experience based on the concept of project-based learning. The classes occurred in a group from the ninth year of elementary school in a public school. The main theme of the project was the olympic spirit in regards to two sport events: OCA (Olimpíada do Colégio de Aplicação da UFRGS) and Rio 2016. Based on the problematization about the theme, we created some tasks which had the text as a core object by covering relevant linguistic resources for the comprehension of genres worked in class. For the final product, we proposed a written production that systematized the discussions made throughout the twelve meetings that were part of our teaching practice.

Keywords: Pedagogy of projects. Olympic spirit. OCA. Rio 2016.

\section{Introdução}

O ensino de Língua Portuguesa deve ter o texto como objeto central. É a partir dele que as tarefas desenvolvidas em sala de aula se delineiam, de forma a tornar o ensino relevante para o aluno, o qual pode enxergar no texto a materialização de sua língua materna. Desse modo, uma forma de se trabalhar com o texto é por meio da prática de ensino pautada na pedagogia de projetos (BARBOSA, 2004; HERNANDÉZ, 2004; VIERA; MENDES, 2004), cuja atuação propõe inovações no ensino ao levar em conta a realidade dos alunos, os quais constroem o conhecimento de forma conjunta ao lado do professor, sem esquecer a relevância do objeto texto. Nesse sentido, este relato tem por objetivo descrever uma prática de ensino de Língua Portuguesa desenvolvida pelas autoras, bem como refletir e discutir a respeito das atividades realizadas em uma turma de $8^{\circ}$ ano do Ensino Fundamental.

Primeiramente, apresentamos a base teórica que sustentou as ideias presentes em nosso projeto. A partir disso, relatamos as partes constituintes de cada etapa, estabelecendo reflexões sobre pontos positivos e negativos dos resultados que obtivemos em sala de aula. Por fim, traçamos algumas considerações finais.

\section{Reflexão teórica}

Trabalhar com projetos é deixar de lado receitas prontas e pensar em propostas que proporcionem um contínuo processo de reflexão sobre as demandas colocadas pela realidade social, que é cada vez mais diversa e desigual. Neste sentido, os projetos devem servir para que se questionem as finalidades dos olhares sobre a realidade, reconhecendo a diversidade, debatendo a objetividade do conhecimento escolar e resgatando vozes excluídas do conhecimento oficial (CORAZZA, 1997). 
Além disso, os projetos devem questionar práticas culturais de forma crítica, abrangendo as diferentes formas de aprender, a fim de que se rompa com uma visão compartimentada e fragmentada da educação escolar. Através dessa pedagogia, é possível que se aborde, se construa e se responda a questões relacionadas à vida dos alunos de forma adequada. Segundo Barbosa (2004, p. 11), "os projetos são elaborados e executados para aprender a estudar, a pesquisar, a procurar informações, a exercer a crítica, a duvidar, a argumentar, a opinar, a pensar".

Sendo assim, o professor tem papel de mediador dentro da pedagogia de projetos. Ele deixa de ser o centro das atenções como "detentor" de saberes e passa a ser parte de uma comunidade de investigação (BARBOSA, 2004), que busca integrar a turma como grupo coletivo em busca de um objetivo comum: a construção do conhecimento. À medida que o aprender está relacionado à elaboração de uma conversação cultural, que tem como fim dar diferentes sentidos ao mundo de forma a constituir uma ponte entre as identidades dos aprendizes, o professor é o agente que possibilita essas trocas, mediandoas e guiando as discussões e reflexões. Dito isso, é fundamental que o professor tenha sensibilidade para conseguir ouvir os alunos e entender quais são suas demandas naquele estágio de desenvolvimento, quais questões os cercam e quais caminhos podem os levar a expandir suas habilidades.

Nesse contexto, se o que se defende aqui é o trabalho com o texto como centro da aula de Língua Portuguesa, é importante destacar a diferença entre alfabetização e letramento. Alfabetização é o processo de aquisição e apropriação do sistema da escrita, alfabético e ortográfico. Ou seja, ser alfabetizado é ter a possibilidade de usar a escrita para as tarefas do cotidiano, o que exige pouco mais do que um processo de decodificação. Já letramento envolve aprender a ler e a escrever para dispor de conhecimento elaborado e poder usá-lo para participar e interagir na sociedade (BRITTO, 2007). Dessa forma, ser letrado significa aprender a ler e a escrever não apenas para o contexto imediato do cotidiano ou apenas como uma competência a ser desenvolvida de forma descontextualizada, mas sim ter contato com diferentes áreas do conhecimento a fim de compreender a realidade. A partir disso, a relação entre os dois conceitos se estabelece no sentido de que a alfabetização precisa ocorrer em um contexto de letramento - não de forma isolada. De modo geral, nossa principal ponderação foi em relação ao letramento dos alunos para os quais o nosso projeto foi desenvolvido. 
Posto isto, a escola deve não apenas ensinar a ler e escrever como um código a ser decifrado para que possamos ler as coisas do mundo, mas, sim, para ler e compreender esse mundo descobrindo-nos como parte dele. Em outras palavras, o letramento também faz parte de um processo de desenvolvimento de identidade (BRITTO, 2007). De forma prática, essa identidade se desenvolve na medida em que as aulas elaboradas são pensadas para um público-alvo específico, garantindo a real participação daqueles alunos nos contextos aos quais são expostos, tanto em sala de aula quanto fora dela.

Falar sobre língua e linguagem parece ser ainda um tabu na escola, como se reflexões dessa origem estivessem restritas apenas à universidade. Entretanto, tudo precisa estar inserido em um contexto para fazer sentido. Isto é, ensinar gramática não fará sentido para o aluno se ele não tiver noção sobre questões fundamentais relativas à língua e linguagem. É dessa forma que se distingue um aprendizado mastigado e decorado - e posteriormente esquecido - de um aprendizado reflexivo e contínuo. Portanto, a gramática é uma etapa para atingir algo muito mais prioritário - o letramento -, e não algo com um fim em si mesmo (SIMÕES, 2012).

\section{O projeto elaborado}

A prática de ensino em questão foi realizada em uma turma de $8^{\circ}$ ano (turma 82) do Colégio de Aplicação (CAp) da Universidade Federal do Rio Grande do Sul (UFRGS), e é resultado de nossa experiência como alunas da disciplina Estágio de Docência em Língua Portuguesa I, no segundo semestre do ano de 2016. Tal disciplina do curso de Licenciatura em Letras da UFRGS conta com 4 horas/aula de observação e 25 horas/aula de docência.

Inicialmente, após aulas teóricas nas dependências da universidade, nós, autoras, partimos para as observações, as quais foram realizadas sob nossos olhares atentos: estávamos interessadas em apreender o contexto no qual os alunos daquela turma estavam inseridos, bem como os seus principais interesses. Sendo assim, após as primeiras observações e debates decorrentes delas, propusemos o projeto intitulado Rio 2016 e Olimpíadas do Colégio de Aplicação: o espírito olímpico presente nas competições. A principal motivação de nossa escolha se deu pelo fato de que os 30 alunos da turma 82 se mostraram interessados em suas discussões quando o assunto era "esporte". Sem hesitar, 
v. 7 (2)

638-656 ago/dez 2017

decidimos por elaborar um projeto cuja temática enfatizaria o espírito olímpico, uma vez que os alunos já haviam participado de competições promovidas pela própria escola e, no ano de 2016, a Olimpíada do Colégio de Aplicação (OCA) teria mais uma edição no mês de setembro. A turma 82 competiria enquanto grupo, isto é, trabalharia coletivamente para o bem de toda a equipe, o que nos levou a optar por trabalhar com espírito olímpico, que também se fez presente no evento recém-encerrado, Rio 2016. Aliando dois aspectos da realidade da turma - a OCA e a Rio 2016 - iniciamos a elaboração do projeto com o consentimento da professora coordenadora da disciplina de Estágio e da professora titular de Língua Portuguesa do $8^{\mathrm{a}}$ ano.

No decorrer da elaboração do projeto, planejamos tarefas que propusessem reflexões acerca da temática a partir de textos reais, isto é, textos que circulam no mundo, fazendo com que os alunos compreendessem o funcionamento de diferentes gêneros textuais, como notícias, reportagens e contos. Buscamos enfatizar diversas habilidades ao longo das aulas, a fim de aperfeiçoar os conhecimentos dos alunos acerca da sua oralidade, leitura e escrita. Tendo em vista a temática do projeto - espírito olímpico -, optamos por realizar atividades em conjunto, ou seja, em duplas, em pequenos grupos ou até mesmo no grande grupo, de forma a promover atitudes de coletividade também em sala de aula e não somente nas competições trabalhadas. Assim sendo, o propósito de nosso projeto incluiu mostrar que atitudes de espírito olímpico são representativas também do nosso cotidiano, além da convivência em sala de aula.

A partir disso, foi elaborada a seguinte proposta nuclear do projeto:

\begin{tabular}{|l|}
\hline PROPOSTA NUCLEAR \\
\hline Temática: Espírito olímpico \\
\hline $\begin{array}{l}\text { Problematização: O que é espírito olímpico e como ele está presente na Olimpíada } \\
\text { do Colégio de Aplicação? }\end{array}$ \\
\hline Gêneros estruturantes: Reportagens, notícias \\
\hline Recursos linguísticos: Verbos \\
\hline $\begin{array}{c}\text { Produto final: Cartazes para a abertura da OCA } \\
\text { Comentário reflexivo sobre a participação da turma no evento } \\
\text { Conto com temática relacionada ao espírito olímpico }\end{array}$ \\
\hline
\end{tabular}

Considerando que um projeto de ensino "envolve uma vasta gama de variáveis, de percursos imprevisíveis, imaginativos, criativos, ativos e inteligentes, acompanhados de uma grande flexibilidade de 
organização" (BARBOSA, 2004, p. 9), as aulas ministradas na turma 82 foram organizadas de modo a culminar em uma produção final. Ou seja, as atividades propostas tinham um elo em comum que permitiram um diálogo constante entre as aulas, facilitando o entendimento do que é um projeto de ensino entre os alunos, ainda que estes não estejam acostumados com uma prática dessa natureza.

Desse modo, nossa proposta de produto final foi constituída de uma soma de tarefas, o que contribuiu para a construção gradual do conhecimento, ao passo que cada atividade englobou diferentes reflexões sobre a temática e fez uso de diferentes aspectos da linguagem. Os Referenciais Curriculares do Estado do Rio Grande do Sul (2009, p. 48) alegam que

[...] é preciso haver sempre novas oportunidades para ler, escrever, solucionar problemas, contrastar, reler, reescrever, melhorar a produção, individual ou coletivamente. Nesse processo, a construção do conhecimento se dáfundamentalmente com o outro e para o enfrentamento de desafios de novos usos das linguagens.

Uma vez que as aulas aconteceram antes e após a OCA, acompanhamos o processo de preparação da turma para a semana dos jogos. Diante disso, a primeira etapa do produto final foi a elaboração de cartazes e o planejamento do desfile da turma para a cerimônia de abertura do evento. Passada a semana da OCA, realizamos a segunda etapa do produto final, cuja proposta foi retomar as aulas anteriores e refletir sobre o desempenho da turma, levando em consideração aspectos como trabalho em equipe e coletividade. Portanto, os alunos debateram sobre a semana da OCA, produzindo uma discussão reflexiva no grande grupo. Chegadas as últimas semanas de aula de nosso projeto, propusemos a última etapa do produto final, que sistematizou tudo o que havíamos trabalhado até então. Em duplas ou trios, os alunos criaram um conto a partir de propostas que envolveram situações simbólicas de espírito olímpico. A seguir, detalhamos o desenvolvimento de nossa prática em sala de aula ao longo do projeto.

\section{Detalhamento das aulas}

A prática de ensino ocorreu ao longo de 12 semanas, durante as quais tivemos 2 encontros semanais com duração de 2 horas/aula. Iniciamos o projeto elaborado colocando em prática a ideia de que as aulas devem dialogar com a realidade dos alunos. De acordo com Vieira e Mendes (2004, p. 26), 
v. 7 (2)

638-656

ago/dez

2017

Nessa postura (pedagogia de projetos), o processo de aprendizagem centra-se na resolução de problemas significativos para o grupo de alunos. Esses problemas geram uma série de necessidades de aprendizagem que vão dando o eixo de estudo e pesquisa ao grupo. o conhecimento, assim, passa a ser uma ferramenta para se compreender melhor a realidade em que se vive. [...] Os conteúdos das disciplinas ganham significado, estudados dentro de um contexto que lhes dá sentido.

Assim, introduzimos o projeto, bem como sua temática, levando para a sala de aula imagens representativas da Rio 2016. Em pequenos grupos, os alunos discutiram as imagens a partir de perguntas motivadoras que guiaram a discussão, o que fez com que grande parte da turma participasse e se mostrasse engajada.

Também na primeira aula, outras duas atividades ocorreram: um jogo sobre curiosidades do mundo olímpico e, por fim, uma pequena produção escrita individual que nos serviu de diagnóstico para verificar as habilidades dos alunos em relação à escrita. O destaque da aula foi a segunda dinâmica, já que o jogo consistiu em dividir a turma em dois grandes times, sendo eles os próprios juízes da brincadeira. Nesse sentido, buscamos introduzir, pouco a pouco, a temática do projeto que estaria presente nas próximas 11 aulas.

Estando aos poucos acostumados com a presença de duas estagiárias em sala de aula, os alunos foram apresentados ao conceito espírito olímpico. Mesmo que o assunto fosse de conhecimento da maior parte da turma, o momento de leitura do texto 10 coisas que são necessárias para o esporte ser olímpico ${ }^{1}$, retirado do site torcedores.com, foi imprescindível para uma melhor compreensão da relevância dessa temática. O momento de leitura se deu de forma conjunta a fim de garantir a leitura integral do texto. Ainda na aula 2, realizamos uma breve discussão das modalidades esportivas presentes na Rio 2016 e dos critérios utilizados na escolha do Comitê Olímpico Internacional (COI) para os esportes disputados. É importante destacar que toda vez que questões específicas de competições olímpicas como a Rio 2016 surgiram, buscamos fazer contrapontos com a OCA, especialmente nas aulas que antecederam tal evento escolar.

Dessa forma, a terceira aula foi dedicada a uma comparação mais aprofundada das modalidades esportivas presentes nas duas competições - OCA e Rio 2016. Também realizamos uma conversa com

$\overline{1}$ Retirado de <http://torcedores.uol.com.br/noticias/2016/07/10-coisas-que-saonecessarias-para-o-esporte-ser-olimpico>. Acesso em agosto de 2016. 
a turma, a fim de levantarmos ideias para a abertura da OCA, uma vez que os alunos seriam avaliados no desfile de abertura e cedemos parte das aulas de Língua Portuguesa para auxiliá-los nesse processo. Para finalizar, jogamos mais algumas rodadas do jogo sobre curiosidades das competições olímpicas.

Na aula seguinte, os alunos assistiram a um vídeo motivacional e debateram em grupos a relação entre o desempenho individual e coletivo no esporte. Além disso, a turma refletiu sobre como o trabalho em equipe é imprescindível para a conquista de um objetivo comum. Com base nessas discussões, foram elencados cinco valores que representam o espírito olímpico na convivência e relacionamento da turma enquanto grupo. A partir disso, os alunos confeccionaram cartazes que foram posteriormente utilizados no desfile da equipe na abertura da OCA. Como já mencionado, essa atividade foi a primeira etapa do produto final do projeto.

A quinta aula aconteceu na semana seguinte à OCA. Por isso, a fim de retomar as aulas anteriores, propusemos a segunda etapa do produto final: um comentário reflexivo sobre o desempenho da turma no evento. Em um grande círculo, cada aluno foi convidado a falar sobre sua experiência enquanto atleta participante dos jogos, tendo em vista o seu desempenho individual e sua contribuição para a equipe. Esse momento foi importante para que os alunos levantassem pontos positivos e negativos da participação da turma como equipe e, assim, refletissem sobre o que poderia ter sido diferente em termos de relacionamento no grupo.

Dado que a turma não conseguiu conquistar a tão almejada vitória, notamos que muitas frustrações surgiram nas falas dos alunos. Por esse motivo, também consideramos esse momento de reflexão um ponto marcante para que os alunos lidassem com seus desapontamentos e aprendessem a ajudar uns aos outros, colocando em prática atitudes de espírito olímpico - temática basilar do projeto. Após esse momento de reflexão e retomada das aulas, os alunos fizeram a leitura individual e conjunta da notícia Espírito olímpico: corredoras que caíram durante prova se ajudam e são classificadas para final mesmo chegando em último², retirada do site www.bbc.com. Feito isso, propusemos discussões em pequenos grupos, que culminaram em uma conversa coletiva sobre aspectos referentes ao gênero e à compreensão do texto.

2 Retirado de <http://www.bbc.com/portuguese/geral-37106111>. Acesso em agosto de 2016. 
v. 7 (2)

638-656 ago/dez 2017

Chegando à metade do projeto, optamos por focar nos recursos linguísticos. Propusemos a leitura da notícia Seleção Feminina é convocada para Rio 201633, de 12.07.2016, divulgada pela assessoria CBF (assessoria de imprensa da Confederação Brasileira de Futebol), dando continuidade ao trabalho com o gênero e iniciando a reflexão sobre os verbos. Antes de realizarmos a leitura propriamente dita, entregamos aos alunos apenas a lista das atletas convocadas, para que pudéssemos dar início às dinâmicas envolvendo os recursos linguísticos. Percebe-se, aqui, a defesa da gramática contextualizada numa perspectiva de ensino do uso da língua, de ação social pela linguagem (RIO GRANDE DO SUL, 2009).

Solicitamos à turma que se organizasse em seis grupos, cada qual contendo um radialista e um repórter. A dinâmica exigiu dos alunos que conseguissem se adaptar à situação proposta, ou seja, cada grupo recebeu a descrição de uma situação inusitada na qual o repórter se encontrava. A lista das atletas convocadas foi comum a todos. Passado um tempo de preparação para a simulação de uma chamada de rádio, os grupos compartilharam o que haviam produzido para o restante da turma.

Concluída essa parte, retomamos a aula com a leitura da notícia e, além de discutirmos seu conteúdo, também abordamos elementos característicos do gênero, relacionando-os com as escolhas verbais colocadas no texto. Tais escolhas verbais foram contrastadas com o tipo de verbo que os próprios alunos utilizaram nas suas chamadas de rádio, atentando-os ao fato de que nem sempre a grande divisão passado presente - futuro exprime unicamente ideias de cada tempo verbal. Ou seja, mostramos a eles que, apesar de a notícia tratar de um fato já ocorrido e, portanto, do tempo passado, os verbos estão na sua maioria no tempo presente, configurando uma característica do gênero notícia.

Na sétima aula, continuamos o estudo do gênero notícia, enfatizando as partes que o constituem. Iniciamos a aula realizando uma atividade de pré-leitura, em que questionamos os alunos a respeito das principais expressões utilizadas não apenas na notícia que seria lida a seguir, mas também no universo esportivo. Além de prepará-los para a leitura, essa atividade teve como objetivo fazer um paralelo entre a linguagem utilizada pelos próprios alunos e aquela presente no texto jornalístico.

Após a leitura integral do texto e da respectiva discussão sobre ele, a turma criou, em grupos, manchetes e lides com base em diferentes

3 Retirado de <https://selecao.cbf.com.br/noticias/selecao-feminina/selecaofeminina-e-convocada-para-rio-2016\#.WeEwU1tSzIU>. Acesso em agosto de 2016. 
perspectivas, colocando-se como redatores da notícia e fazendo uma releitura do que acabaram de ler. Abaixo, o enunciado da tarefa entregue aos alunos seguido de uma das releituras esperadas:

Nomes:

\section{Tarefa escrita:}

Como vimos, a manchete é uma parte importante da notícia. É ela que antecipa o que será abordado e indica o teor da notícia. Ou seja, se o texto apresenta fatos positivos sobre o que está sendo noticiado, a manchete também será escrita de forma positiva. Caso o teor da notícia seja negativo, pejorativo, irônico, etc., a manchete muito provavelmente seguirá essa linha de raciocínio.

Sendo assim, imagine que você é o redator da notícia que acabou de ler. Reescreva a manchete pensando que a notícia trata da falta de profissionalismo do técnico da seleção. Não esqueça de ser criativo em sua manchete!

Após o intenso trabalho com os gêneros notícia e reportagem, a oitava aula foi dedicada à retomada dos recursos linguísticos. Considerando as possíveis abordagens gramaticais sobre o sistema verbal, propomos uma compreensão global do funcionamento dos verbos na construção de um texto. Para isso, os alunos foram apresentados a uma notícia sobre o desempenho da seleção feminina de futebol na Rio 2016 e a perguntas que os guiaram na tarefa de depreender os sentidos do texto. Nesse processo, enfatizamos a variedade de verbos, explorando aspectos como modo, tempo, número e pessoa e exemplificando não somente com frases retiradas da própria notícia lida, mas também com frases produzidas pelos próprios alunos. Dessa forma, estabelecemos uma construção conjunta para o entendimento dos verbos, uma vez que colocamos os alunos na posição de investigadores da língua.

A aula 9 se constituiu de três momentos. Iniciamos com a construção de uma linha do tempo dos tempos verbais, a fim de resgatar o trabalho da aula anterior e consolidar a compreensão da tríade passadopresente-futuro. O objetivo dessa primeira atividade foi preparar a turma para a tarefa que viria a seguir, na qual os alunos ordenaram contos. Pequenos grupos receberam uma história cortada em partes, devendo encaixar cada parte da história no tempo verbal predominante. A ideia foi fazer com que os alunos percebessem que, em um conto, os fatos narrados não acompanham a cronologia dos tempos verbais, mas sim 
o enfoque de sentido preterido pelo autor. Além disso, demos início ao trabalho com o gênero base da produção final que aconteceu na aula seguinte.

Para finalizar essa aula, propomos uma dinâmica oral de contação de história coletiva. Em roda, os alunos criaram uma história com base em imagens e tempos verbais variados sorteados na hora. A história tomou rumos inesperados à medida que o sorteio aconteceu, provocando risos e uma atmosfera de descontração.

A décima aula foi dedicada à primeira etapa da produção final escrita (vide anexo 1). Após a definição conjunta dos critérios de avaliação dos textos e retomada dos principais pontos do projeto discutidos ao longo das aulas, os alunos receberam propostas para a produção textual. Criamos cinco situações acerca da temática espírito olímpico em que delimitamos personagens, espaço e situação-problema. A partir disso, em duplas ou trios, os alunos produziram um conto utilizando os recursos linguísticos estudados, bem como a situação base que receberam. A seguir, ilustramos uma das propostas de produção textual:

\section{Produção final:}

$\rightarrow$ Crie um conto de no mínimo uma página a partir da situação em que os personagens se encontram. Você deverá narrar toda a trajetória do personagem, ou seja, os acontecimentos iniciais, a situação problema a ser resolvida e também o desfecho da história.

Seja criativo e tenha em mente as discussões realizadas em aula sobre o espírito olímpico em competições como a Olimpíada e a OCA.

\section{Situação 5:}

Em seu primeiro dia de aula no Colégio de Aplicação, um novo aluno é comunicado sobre a OCA. Ao tentar fazer amizade com seus novos colegas, percebe que teria um ano difícil, pois, além de ser um ambiente totalmente novo, repleto de experiências nunca antes vivenciadas, percebeu que os seus colegas ficavam em grupos extremamente fechados e ele não teria espaço para conquistá-los. Com a OCA se aproximando, as equipes foram se organizando e o novo aluno continuava excluído. Uma semana antes do término das inscrições, algo inesperado acontece e o aluno encontra o seu lugar.

Conforme planejado, na aula 11 os alunos realizaram a reescrita dos textos produzidos na aula anterior. Considerando que todo texto precisa ser reescrito (SIMÕES, 2012), lemos as primeiras versões priorizando aspectos referentes ao conteúdo em detrimento da forma. Nesse sentido, examinamos a profundidade de cada texto, isto é, buscamos enxergar as maneiras pelas quais os alunos se expressaram através da escrita e como imprimiram suas marcas de autoria.

De modo a encaminhar a reescrita, reunimos as primeiras versões e, com base nos critérios de avaliação anteriormente delimitados, 
realizamos a leitura dos textos. A fim de organizar a avaliação das produções, criamos uma tabela norteadora com os seguintes critérios: adequação ao tema, criatividade, linguagem e formato - todos contendo 3 níveis de pareceres, a saber, muito bom, bom e parcial. Entendemos por adequação ao tema a capacidade de os alunos respeitarem a proposta de produção textual, buscando solucionar a situação-problema do personagem. Em relação à criatividade, observamos o empenho dos alunos no que tange aspectos de inventividade e originalidade no desfecho que deram a cada trama. O critério linguagem diz respeito aos elementos de coesão e coerência, ou seja, o texto deve estar semanticamente adequado: é preciso que o autor do texto possibilite ao leitor uma leitura clara, sem causar dificuldades de apreensão dos sentidos. Por fim, formato se refere à estrutura adotada por cada dupla ao colocar a narrativa no papel, atentando para elementos como letras maiúsculas e minúsculas, pontuação, organização de parágrafos e extensão do texto.

Os quatro critérios acima serviram de base para nossa prática enquanto revisoras das produções textuais. Fornecemos feedback para cada texto por meio de comentários em forma de bilhetes, o que possibilitou que, ao invés de apontarmos e corrigirmos somente erros gramaticais, sublinhássemos partes incoerentes e problemáticas e sugeríssemos modificações das mesmas. Dessa forma, tais comentários facilitaram não somente o nosso trabalho de correção, mas também exigiram dos alunos uma atitude reflexiva acerca das suas próprias produções, uma vez que os convidamos a repensar sua prática enquanto autores. Mangabeira, Costa e Simões (2011, p. 296) pontuam que

A reescrita orientada por bilhetes constitui-se como uma maneira de avaliação dos textos que vai além do que se intitula correção indicativa, correção essa que visa apenas a apontar erros e problemas no texto do aluno. O objetivo da reescrita na sala de aula é que o texto escrito pelo aluno seja um ponto inicial no percurso de aprendizagem e apropriação, por parte desse aluno, das propriedades discursivas e comunicativas dos gêneros em questão, permitindo que ele se posicione como autor de seu texto, que escreva para um determinado interlocutor, com determinados objetivos, sendo ambos relativos à situação de interlocução proposta pela tarefa pedagógica a que seu texto responde.

É importante salientar que, durante todo o processo de escrita e reescrita, circulamos entre as duplas e trios de forma a solucionar dúvidas e ajudá-los. 
v. $7(2)$

638-656 ago/dez 2017

Para finalizar o projeto, propomos uma última aula para o compartilhamento das produções textuais e para a avaliação do andamento das aulas. Em círculo, cada dupla leu seu conto para os demais colegas, enquanto que estes comentaram o que acharam da história ao fim da leitura. Dessa forma, buscamos promover um momento de troca, em que os alunos puderam opinar e dar respostas aos textos, colocando-se na posição de interlocutores na medida em que estabeleceram uma atitude responsiva em relação aos textos dos colegas autores. Assim, a "leitura [atua e atuou como] uma atividade de construção numa relação produtiva de interação entre o texto e o leitor" (NAUJORKS, 2011, p. 103).

A avaliação do projeto Rio 2016 e Olimpíada do Colégio de Aplicação: o espírito olímpico presente nas competições constituiu-se da análise de pontos importantes das aulas, informando se os critérios foram cumpridos, parcialmente cumpridos ou não cumpridos (vide anexo 2). Primeiramente, os alunos avaliaram o projeto de uma forma geral, sendo questionados a respeito da temática, do entendimento de conceitos-chave, da contribuição do produto final e da relevância das tarefas realizadas ao longo das 12 aulas. Em um segundo momento, cada aluno avaliou o seu próprio desempenho nas aulas, considerando aspectos como assiduidade, participação, comprometimento e respeito aos colegas e professoras. Por último, em um espaço dedicado à reflexão, os alunos relataram, de forma escrita, pontos do projeto a serem repensados.

\section{Considerações finais}

O projeto de ensino Rio 2016 e Olimpíada do Colégio de Aplicação: o espírito olímpico presente nas competições, desenvolvido na turma 82 do Colégio de Aplicação (CAp) da UFRGS, proporcionou diferentes aprendizados. Como estagiárias de Língua Portuguesa, podemos destacar pontos positivos e negativos de nossa prática em sala de aula. Em primeiro lugar, percebemos que o real aprendizado se dá quando o aluno é colocado em uma posição de protagonista em seu próprio processo de aprendizagem (RIO GRANDE DO SUL, 2009). Para que isso efetivamente aconteça, é necessário um planejamento voltado especificamente para um público. Desse modo, não perdemos de vista que nosso público-alvo era a turma 82. Em outras palavras, desde as observações até a décima segunda aula, nosso planejamento sofreu constantes adaptações para que as aulas fossem relevantes e engajassem minimamente os alunos. 
Tendo em vista que um projeto de ensino possui uma temática norteadora, as aulas devem estar em contínuo diálogo umas com as outras, o que pode provocar diferentes reações dos alunos. A avaliação realizada na última aula nos mostrou que muitos deles ainda não estão familiarizados com esse tipo de pedagogia, uma vez que manifestaram vontade de explorar diferentes temáticas além do que propomos para espírito olímpico. Constatamos também que alguns alunos encararam certas atividades - tais como jogos e tarefas de discussão - como momentos de não-aprendizado por estas não estarem de acordo com o ensino tradicional centralizado na gramática. No entanto, defendemos que um ensino legítimo de gramática é aquele contextualizado e que tem como objeto central o texto.

Nessa mesma perspectiva, Schlatter (2009) argumenta que o ensino de línguas deve solucionar problemas do aqui e do agora, isto é, a aula de língua, e consequentemente a aula de Língua Portuguesa, deve ser um espaço em que o aluno seja instigado a agir no mundo. Portanto, em nossa prática em sala de aula, buscamos propor tarefas relevantes que envolvessem textos reais que circulam nas diferentes esferas sociais. Do mesmo modo, a proposta de produto final permitiu que resgatássemos a temática e as discussões realizadas desde o primeiro encontro, possibilitando uma atitude reflexiva dos alunos, os quais materializaram a língua nos contos que produziram.

Embora a disciplina de Estágio de Docência em Língua Portuguesa I preveja apenas 25 horas de prática docente, nossa experiência enquanto estagiárias foi rica para que aprendêssemos estratégias de planejamento e abordagens de ensino para os doze encontros. Nesse sentido, destacamos a importância de levar em consideração as inquietações e as preferências dos alunos, para, a partir disso, desenvolver aulas profícuas e relevantes para o curto período de tempo que tivemos. As diferentes situações que encontramos em sala de aula e que nos fizeram rever semanalmente nosso planejamento foram intensas e, portanto, essenciais para a nossa formação.

\section{Referências}

BARBOSA, M. C. S. Por que voltamos a falar e a trabalhar com a Pedagogia e Projetos? Projeto - Revista de Educação: Projetos de trabalho, v. 3, n. 4, p. 8-13. 2004.

BRITTO, Luiz Percival Leme. Escola, ensino de língua, letramento e conhecimento. Calidoscópio, n. 1, v. 5, p. 24-30, 2007. 
V. 7 (2)

$638-656$ ago/dez 2017

CORAZZA, Sandra Mara. Planejamento de ensino como estratégia de política cultural. In: MOREIRA, Antônio Flavio B. (Org.). Currículo: questões atuais. Campinas: Papirus, 1997. p. 103-143.

HERNÁNDEZ, F. Os projetos de trabalho: um mapa para navegantes em mares de incertezas. Projeto - Revista de Educação: Projetos de trabalho, v. 3, n. 4, p. 2-7. 2004.

MANGABEIRA, A. B; COSTA, E. V. SIMÕES, L. J.. O Bilhete Orientador: Um gênero discursivo em favor da avaliação de textos na aula de línguas. Cadernos do IL. Porto Alegre, n. 42, p. 293-307, 2011.

NAUJORKS, J. da C. Leitura e enunciação: princípios para uma análise do sentido na linguagem. 2011. 153 p. Tese (Doutorado em Letras) - Programa de Pós-Graduação em Letras/UFRGS, Rio Grande do Sul. 2011.

RIO GRANDE DO SUL. Referenciais Curriculares do Estado do Rio Grande do Sul: linguagens, códigos e suas tecnologias / Secretaria de Estado da Educação. - Porto Alegre: SE/DP, 2009.

SCHLATTER, M.. 0 ensino de leitura e língua estrangeira na escola: uma proposta de letramento. Calidoscópio, n. 1, v. 7, p. 11-23, 2009.

SIMÕES, L. J.. Leitura e autoria: planejamento em Língua Portuguesa e Literatura; colaboração de Ana Mariza Filipouski, Diana Marchi e Joice Welter Ramos; ilustrações de Eloar Guazzelli. Erechim: Edelbra, 2012.

VIEIRA, L. H. A. e MENDES, V. Os projetos de trabalho: um espaço para viver a diversidade e a democracia na escola. Projeto - Revista de Educação: Projetos de trabalho, v. 3, n. 4, p. 25-29. 2004.

Recebido em: 15 de fev. de 2017.

Aceito em: 26 de jul. de 2017. 


\section{Anexos}

\section{Anexo 1}

Figura 1 - Primeira versão com bilhete orientador (página 1)

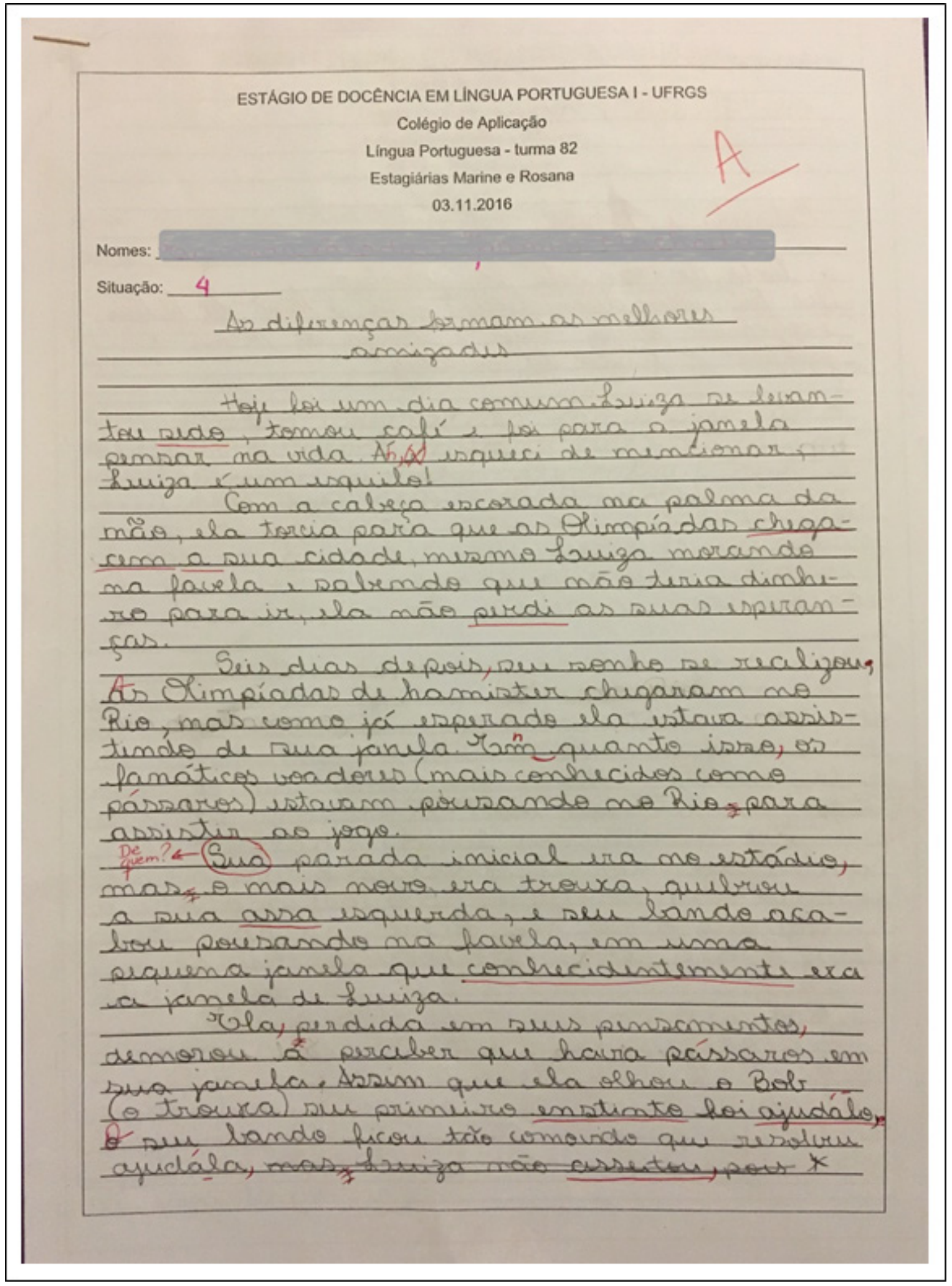




\section{v. 7 (2) 638-656 ago/dez 2017}

Figura 2 - Primeira versão com bilhete orientador (página 2)

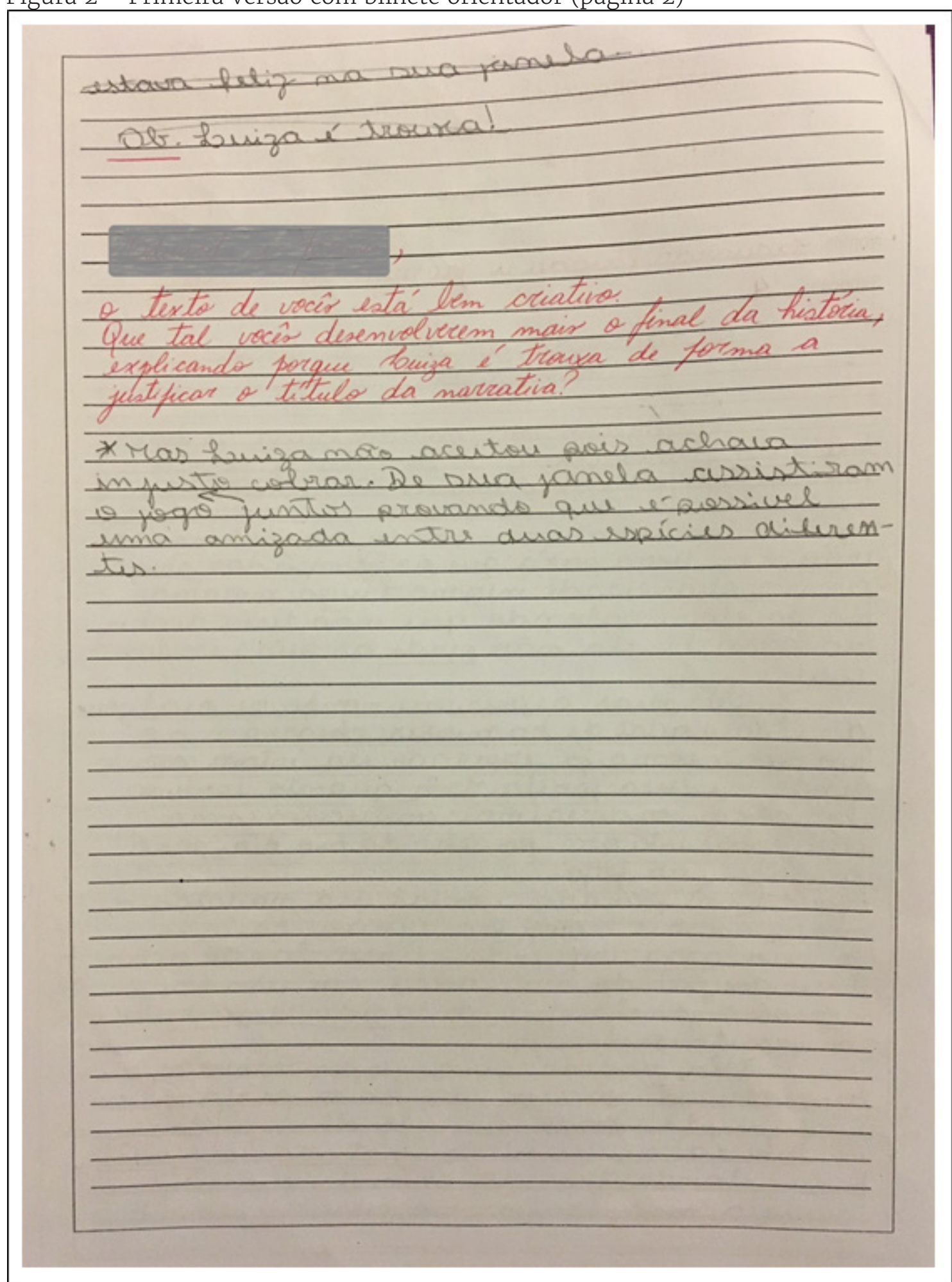




\section{Anexo 2: Formulário de avaliação final do projeto}

Nome:

\begin{tabular}{|l|l|l|l|}
\hline \multicolumn{1}{|l|}{$\begin{array}{l}\text { Avaliação doProjeto Rio } 2016 \text { e Olimpíada do Colégio de Aplicação: o espírito olímpico } \\
\text { presente nas competições }\end{array}$} & \multicolumn{1}{|l|}{} \\
\hline $\begin{array}{l}\text { O tema do projeto estava de acordo com minhas } \\
\text { necessidades? }\end{array}$ & Sim & Parcialmente & Não \\
\hline O projeto me fez refletir sobre 'espírito olímpico'? & & & \\
\hline $\begin{array}{l}\text { A produção final do projeto (narrativa) esteve de } \\
\text { acordo com o que foi trabalhado ao longo das aulas? }\end{array}$ & & & \\
\hline $\begin{array}{l}\text { As atividades desenvolvidas ao longo das aulas } \\
\text { contribuíram para o meu aprendizado? }\end{array}$ & & & \\
\hline $\begin{array}{l}\text { As atividades trazidas pelas professoras foram } \\
\text { relevantes? }\end{array}$ & & & \\
\hline As professoras souberam lidar com a turma? & & & \\
\hline $\begin{array}{l}\text { Espaço para sugestões: } \\
\text { O que poderia ter sido diferente? }\end{array}$ & & \\
\hline
\end{tabular}

Autoavaliação: o que aprendi no projeto Rio 2016 e Olimpíada do Colégio de Aplicação: o espírito olímpico presente nas competições

\begin{tabular}{|l|l|l|l|}
\hline & Sim & Parcialmente & Não \\
\hline $\begin{array}{l}\text { Estive presente nas aulas e participei quando } \\
\text { solicitado? }\end{array}$ & & & \\
\hline Busquei auxiliar os colegas quando necessário? & & & \\
\hline $\begin{array}{l}\text { Me comprometi em melhorar minhas } \\
\text { habilidades de leitura e escrita? }\end{array}$ & & & \\
\hline Respeitei os colegas e as professoras? & & & \\
\hline
\end{tabular}

Espaço para reflexão:

O que eu poderia ter feito diferente?

Como posso melhorar? 
Espírito olímpico em sala de aula...

$$
\text { v. } 7 \text { (2) }
$$
638-656 ago/dez 2017

656 